This item was submitted to Loughborough's Research Repository by the author.

Items in Figshare are protected by copyright, with all rights reserved, unless otherwise indicated.

\title{
Understanding and enhancing future infrastructure resiliency: a socio- ecological approach
}

\section{PLEASE CITE THE PUBLISHED VERSION}

http://dx.doi.org/10.1111/disa.12114

\section{PUBLISHER}

John Wiley \& Sons Ltd (@ The Author(s)/Overseas Development Institute)

\section{VERSION}

AM (Accepted Manuscript)

\section{PUBLISHER STATEMENT}

This work is made available according to the conditions of the Creative Commons Attribution-NonCommercialNoDerivatives 4.0 International (CC BY-NC-ND 4.0) licence. Full details of this licence are available at: https://creativecommons.org/licenses/by-nc-nd/4.0/

\section{LICENCE}

CC BY-NC-ND 4.0

\section{REPOSITORY RECORD}

Sage, Daniel J., Indraneel Sircar, Andrew R.J. Dainty, Pete Fussey, and Chris I. Goodier. 2019. "Understanding and Enhancing Future Infrastructure Resiliency: A Socio-ecological Approach". figshare. https://hdl.handle.net/2134/18995. 


\section{Understanding and Enhancing Future Infrastructure Resiliency:}

\section{A Socio-Ecological Approach}

Word count: 7760 (excluding references)

\section{Abstract}

It has long been recognized that the resilience of any system, whether human or natural, involves the capacity of that system to adapt its structure, although not necessarily function, to a new configuration in response to long-term socio-ecological change. Thus over the long-term, enhancing resilience involves more than simply improving the ability of a system to resist an immediate threat or recover to a stable, past state. However, despite the prevalence of adaptive notions of resilience in academic discourse, it is apparent that infrastructure planners and policies largely continue to struggle to comprehend longer-term system adaptation in their understandings of resilience. Instead a short-term, stable system perspective (STSS) on resilience is prevalent: our purpose here is to identify and problematize this perspective. In so doing, we present research that developed a heuristic 'scenario-episode' tool to address, and challenge, this STSS perspective as it plays out within the context of UK infrastructure resilience. Thus, our goal is to help resilience practitioners better understand the capacities of future infrastructure systems to respond to natural and malicious threats.

Keywords: Resilience, Critical Infrastructure Protection, Scenario Methodologies 


\section{Introduction}

Resilience is often conceptualized as a long-term adaptive, transformative process, (Adger, 2000; Coaffee et al, 2009; Holling, 1973; Manyena, 2006; Paton et al, 2000). Adaptive conceptualizations of resilience have been maintained across many fields: from ecologists seeking to understand the impact of past climate change events on the potential of corals to survive future climate change (Pandolfi, 2003), to psychologists seeking to understand how childhood is formative in equipping individuals to adapt to future stress (Richardson, 2002). Regarding physical infrastructure systems, it is increasingly recognised that, whilst they can never be totally resistant, they should be designed in a manner that allows for recovery of their structure and function following a catastrophic event (Bosher and Dainty 2010; Coaffee et al, 2009). And yet the structure and function of infrastructure systems is far from static over the longer-term. Historical studies reveal how physical infrastructure systems, whether transport (Guldi, 2012) or energy (Hughes, 1983), have evolved over decades in unpredictable ways as they respond to, and further shape, socio-ecological changes. In the context of critical infrastructure planning, including emergency response ${ }^{1}$, policy debates remain largely silent on the capacity of infrastructure systems to adapt to longer-term socioecological changes. Instead, infrastructure resilience policy and planning has become largely orientated around a short-term, stable system (STSS) perspective. In essence, STSS perspectives focus on how a known socio-technical system (e.g. electricity grid) can either resist an immediate short-term threat (such as a bomb or flood), or else rapidly bounce back

\footnotetext{
${ }^{1}$ In keeping with UK policy, we regard emergency response as a critical infrastructure system in its own right (Cabinet Office, 2011: 12).
} 
from that threat to an original, equilibrium state (see e.g. Cabinet Office, 2010; Cabinet Office, 2011; Xu et al, 2012; Maliszewski and, Perrings, 2012).

In this paper we aim to identify and problematize the prevalence of STSS perspectives of resilience as related to infrastructure. We argue that this enables a better understanding of the relationship between open-ended adaptations in infrastructure systems in response to longer-term socio-ecological changes, such as climate or economic change, and the shortterm capacity of infrastructure systems to resist and recover from immediate, often wellknown, threats. Thus, in this paper we address two related questions: (i) what are the limitations of the STSS perspective, and (ii) how can scholars and practitioners address the limitations of this perspective as a basis for improving resilience in specific contexts. The contributions we propose are conceptual and methodological: to evaluate the conceptual and methodological value of a heuristic tool to elicit new debates around the resiliency implications of infrastructure changes. To this end, rather than offering prescriptive recommendations of how resilience practice should be enacted (which is beyond the scope of this paper), we discuss policy interventions derived from this approach to develop conceptual and methodological arguments and illustrate the shorter-term implications of long-term events.

After introducing some of the key conceptual debates around 'infrastructure' and 'resilience' that inform the analysis of this paper, the first section reviews the significance, and by extension limitations, related to the STSS perspective within current resilience policy and planning. This section will refer to global resilience policies, but will focus on UK 
infrastructure resilience policy and planning as a detailed case study. However, we recognize that simply critiquing the existence and potential consequences of temporal, and conceptual, myopia, within current critical infrastructure planning leaves the limitations of the STSS perspective unaddressed for practitioners. For this reason, in the second section of the paper we outline an alternative way of framing infrastructure resilience. Here, a novel heuristic method informed by scenario methodologies and to help practitioners capture the consequences of longer-term, open-ended adaptations within critical infrastructure resilience for their resilience work, organisations and policies is presented. Drawing upon the parlance of Holling $(1973,2001)$, we term this approach the 'socio-ecological' perspective. In the third section of the paper we evaluate the utility of this heuristic method to elicit new policy-relevant insights into resilience that enable longer-term changes and adaptations to become foregrounded. Here we discuss a multi-disciplinary research project in which this methodology was recently employed as an aid to better understand future UK infrastructure resilience, specifically in the key infrastructure areas of energy and transport. By way of conclusion we briefly examine the wider value and transferability of this approach to a range of resilience practitioners, as well as possibilities for further research in this area. Before proceeding further it is important to clarify how two terms that will be repeatedly mobilized within this paper to frame the research problem are being understood: 'resilience' and 'infrastructure'.

1.2 Framing Resilience and Infrastructure 
One much-cited (see Folke, 2006; Manyena, 2006; Walker and Cooper, 2011), and elucidating, definition of resilience, germane to the focus of this paper, is that proposed by the ecologist C.S. Holling. In a seminal paper, Holling (1973) explained how system behaviour can be understood through two disciplinary lenses: engineering and ecology. In an engineering system the parts of system must perform consistently within a narrow, stable range of measurable variables. For example, an electricity grid must transmit energy at a particular frequency. Any deviation from such narrow performance goals must be counteracted. By contrast, in an ecological system, where external threats are often unknown, systems can be understood through less defined qualitative relationships; for example, focusing on the survival of a species in the eco-system, rather than numbers of a species. Holling (1973) describes the ecological model as a better basis to conceptualize resilience because if the persistence of relationships is what guarantees the survival of a system - rather than the avoidance of temporary oscillations in that system's performance then resilience does not equal stability. Consider the example of an energy grid. The resilience of the electricity grid is not the same as its stability. Resilience requires that the qualitative relationship between various parts of the network are maintained (e.g. coal power stations are linked through a coal supply chain to a coal seam, then linked to consumers via a transmission network composed of control centres, pylons and substations). Here, resilience constitutes more than simply the constant operation of the system in terms of set frequency and voltage. Indeed, without the perseverance of such qualitative functional relationships, quantitative system stability and structural integrity cannot even be measured. Holling is not suggesting here that quantitative stability is not important, rather that it is not sufficient in itself to understand, and achieve, resilience. Holling (1973) also observes how systems appear more resilient to change by virtue of their 
instability; insects in forests with high climatic variability suffer immense population shifts, but recover well. Insects in areas of low climatic fluctuation recover far less well. We could similarly hypothesize that areas of the world with highly unstable energy networks promote better recovery and adaptation to power loss within a human population than highly stable infrastructures.

More recently, Holling (2001; and Holling et al., 2002) has refined his ideas through the 'panarchy' model of change in socio-ecological systems. This cycle contains two phases: the long and slow accumulation of resources for conservation and transformation by the system and shorter periods of innovation and reorganisation. In the first phase, stability, connectedness and rigidity in the system increase; yet this also increases the vulnerability of the system to change. In the second phase, an external event exposes this vulnerability causing rapid systemic disorganisation where new relationships are unexpectedly formed, sowing the seeds of future renewal. Holling (2001) argues that during the first stage, systems at different temporal scales are mostly immune to changes at lower scales, so that, for example, a single decision in a company does not influence national law. Yet, there are opportunities for cross-scale interaction, for example when this law is too rigid and eventually fails during the second stage, a single decision could influence its renewal. Additionally, larger scales can also release stabilizing influences on smaller scales as they break down, releasing learnt behaviours to constrain the renewal of smaller, faster systems (Holling, 2001). 
Holling's $(1973 ; 2001)$ work has two important implications that help us challenge an STSS perspective on resilience. First, Holling's (1973) early work draws a useful distinction between resilience and stability and reveals an important relationship between the two. There can be no quantitative system stability without qualitative resilience. Yet, qualitative resilience does not require quantitative system stability and, indeed, for Holling, quantitative system stability may actually weaken resilience. We should add an important clarification at this juncture: we are not proposing that system stability and reliability is undesirable. Rather, we should contextualize this STSS perspective, via Holling (1973), to suggest that short-term stability should never be the end-goal of resilience thinking, as it obscures the adaptive, open-ended, nature of systemic resilience. Second, Holling's (2001) later work suggests that all systems adaptation is endemic, albeit over different time frames. However, we cannot grasp adaptation in any system without acknowledging the complex interactions between different adaptive cycles of different (yet related) systems operating across varying temporal and spatial scales. In other words, any attempt to understand resilience purely through an isolated single system and its temporal (and spatial) scale will obscure our understanding of the broader resilience innovations and constraints. Holling's socio-ecological notion of resilience fundamentally challenges the STSS perspective found in notions of resistance, reliability and recovery in much current resilience policy and planning (see Cabinet Office, 2010; 2011; UN, 2005; Patriot Act, 2001).

Another key term addressed here is 'infrastructure'. This term can be refined in relation to the physical and organisational assets required not simply to maintain the normal running of a nation-state, but whose loss would bring about significant, long-term, socio-economic 
deterioration in that state. This is the domain of critical infrastructure. Numerous definitions of critical infrastructure exist in policy documents. Arguably the most significant is that within the 2001 US Patriot Act:

The term "critical infrastructure" means systems and assets, whether physical or virtual, so vital to the United States that the incapacity or destruction of such systems and assets would have a debilitating impact on security, national economic security, national public health or safety, or any combination of those matters (Patriot Act 2001: P.L. 107-56).

This is the established US definition and has been translated into other policy documents worldwide, including the UK:

Those infrastructure assets (physical or electronic) that are vital to the continued delivery and integrity of the essential services upon which the UK relies, the loss or compromise of which would lead to severe economic or social consequences or to loss of life (Cabinet Office, 2010: 8).

Such broad policy definitions inevitably pose more questions than they answer. Specifically, how do the various organisations involved in the planning, maintenance and protection of infrastructure understand what is 'critical' and what is not (CRS, 2004; Manyena, 2006)? While policy habitually narrows down critical infrastructure to specific sectors (see Cabinet Office, 2010; Patriot Act, 2001), governments often ask private sector organisations to 
maintain lists of critical infrastructure in conjunction with government agencies (such as the Office of Infrastructure Protection (US) or Centre for the Protection of National Infrastructure (UK)). In the case of the US, some reports have challenged the accuracy of these lists, as different public and private bodies disagree over the criticality of assets (CRS, 2004: 16). In many respects such ambiguity is unavoidable, as mapping critical assets in fast changing infrastructure systems, especially in sectors like ICT (Information Communication Technologies), would be impossible to fully determine (CRS, 2004). Nevertheless, it is important to note the problems defining and mapping current critical infrastructure resilience, when considering the challenge posed here of thinking about critical infrastructure resilience over the longer-term.

In the next section we will examine how critical infrastructure resilience is currently being defined, understood and addressed, across three scales of policy and practice: first, global definitions of resilience; second, UK critical infrastructure policy documents; and third, emergency planning events. Taken together, analysis of these scales reveals the prevalence of the STSS view in contemporary resilience practice, especially in relation to critical infrastructure. Following Holling $(1973,2001)$, we argue that a key problem here is that such perspectives both overlook the potential and challenge of adaptation that is common to all systems, and downplay the interactions between systems and their scales that constitute resilience.

\section{Resilience Today: Temporal and Conceptual Myopia in Policy and Practice}


Some of the most significant definitions of resilience in current international policy discourse are contained in the documents produced by the United Nations Office for Disaster Risk Reduction (UNISDR). In 2005 the Hyogo Framework for Action: Building the Resilience of Nations and Communities to Disasters (HFA) was produced by the UNISDR, supported by the General Assembly through UN resolution 60/195, setting out an ambitious plan to improve global resilience to natural and human-induced hazards (UN, 2005). The HFA offers a set of guiding principles and practical means to increase global resilience up to 2015. The HFA defines resilience as:

The capacity of a system, community or society potentially exposed to hazards to adapt, by resisting or changing in order to reach and maintain an acceptable level of functioning and structure. This is determined by the degree to which the social system is capable of organising itself to increase this capacity for learning from past disasters for better future protection and to improve risk reduction measures (UN, 2005: 4).

While superficially similar to the definition of resilience proposed by Holling $(1973,2001)$, the HFA definition diverges significantly. Notably, the HFA does not admit the capacity for adaptation to be engendered through the creative destruction of a system. Also, there is no mention of how resilience might be induced through the interaction of multiple systems, changing over different spatial and temporal scales. Rather, it appears, and contra Holling (2001), that adaptive resilience usually occurs as a single, isolated system becomes more robust and resists change. Holling $(1973 ; 2001)$ denies this possibility: a more stable, rigid 
system is always less resilient and more vulnerable. Holling (2001) contends that the adaptive resilience of any system must be understood alongside other systems. However, while challenging the mutual exclusivity of stability and resilience proposed by Holling (1973, 2001), the HFA definition does suggests that resilience may also occur through adaptation and change. In effect, the HFA defines resilience in a manner that both encapsulates and diverges from Holling $(1973,2001)$. However, as the guidance begins to detail more specific advice for particular systems, and especially as related to infrastructure, it shifts noticeably away from change towards resistance as a model of adaptive resilience. This excerpt on how to implement critical infrastructure resilience evidences this shift:

Protect and strengthen critical public facilities and physical infrastructure, particularly schools, clinics, hospitals, water and power plants, communications and transport lifelines, disaster warning and management centres, and culturally important lands and structures through proper design, retrofitting and re-building, in order to render them adequately resilient to hazards (UN, 2005: 11).

The HFA is an important document that supports the efforts of both front-line practitioners and governments working to improve resilience across the world (Manyena, 2006). However, viewed against Holling's $(1973,2001)$ understanding of resilience, the HFA could be characterized as myopic both conceptually, through its emphasis on stability, and temporally, through its focus on adaptation in single systems adapting over short timescales to immediate hazards. To understand how national governments have aligned their policies with the HFA, and by extension instituted its short-term, stability orientated 
approach to resilience, especially in the field of infrastructure, we will now turn towards UK resilience policy.

The UK Civil Contingencies Secretariat (CCS) recently defined resiliency as the process through which "assets, networks and systems anticipate, absorb, adapt to and/or rapidly recover from a disruptive event" (Cabinet Office, 2011: 15). This process has been subdivided into four elements: "resistance; reliability; redundancy; response and recovery" (Cabinet Office, 2011: 15, see also Cabinet Office, 2010). In the case of infrastructure, the CCS defines a measure of resilience as security of the supply of a service, particularly within critical national infrastructure (Cabinet Office, 2010: 7). The CCS prioritizes critical national infrastructure (CNI) as central to societal resiliency, wherein the "loss or compromise of which would lead to severe economic or social consequences or to loss of life" (Cabinet Office, 2010: 8). Nine critical infrastructures have been defined by the Cabinet Office: finance, health, food, government, emergency services, transport, energy, communications and water (Cabinet Office, 2011: 12). These descriptions of critical infrastructure resiliency are broadly in keeping with those of other nations, for example the US (see NIAC, 2009).

Significantly, these understandings of 'resilience' focus on short-term, system stability thus repeating the same STSS notion of resilience as the HFA. This is evidenced in at least two ways. First, there is an emphasis on recovery back to a stable system, with change being treated as the threat to the system, rather than a possible mode of resiliency in itself. This is apparent in the four-fold definition of 'Resilience' from the CCS (Cabinet Office, 2011). Notions of 'Resistance', 'Redundancy' and 'Reliability' do not suggest the possibility of 
change and adaptation. Rather, they point to the possibility of rendering a system more robust to any change. The fourth element, 'Response and Recovery', might be expected to contain the possibility of adaptive structural change. However, CCS policy indicates otherwise, instead defining this feature as purely the "ability, capacity and capability to respond and recover from disruptive events" (p17). Secondly, there is a focus within the CCS on the probabilistic measurement of anticipated risk in the short-term, despite the founding principles of the CCS to engage with unfamiliar, longer-term events (Smith, 2003). For example, the CCS conducts an on-going National Risk Assessment, from which a declassified National Risk Register (NRR) is published. The NRR is produced to aid different organisations in improving their resilience across the four CCS resilience elements, including participation in emergency training and exercises, as is compulsory for all governmental front-line organisations under the 2004 Civil Contingencies Act. Notably, the horizon of the NRR is limited to five years.

While some may dismiss such international and national resilience policy as little more than rhetoric, we can also find evidence that this STSS view of resilience is consequential within practices linked to resilience, for example UK emergency planning exercises. Such exercises provide an authoritative setting through which future 'resilience' is rendered comprehensible and actionable to practitioners with a stake in protecting critical infrastructure systems. Given the policy discourse on resilience, it is unsurprising that recent ethnographic research into UK emergency response exercises has revealed a deliberate focus on ensuring plausibility (see Anderson and Adey, 2011). This strategy permits only minimal changes in infrastructure contexts from the current status quo and relatively well- 
known hazards to be used within exercise scenarios: "They anchor the interval of emergency in 'realistic' details that resonate with players' tacit and codified knowledges of the area, the exercised event, and response behaviour" (Anderson and Adey, 2011: 1100). In other words, UK emergency planning exercises appear more or less predicated on an STSS view of resilience.

While this STSS orientation towards resilience is no doubt beneficial as a means of testing the efficacy of current procedures, assets and policies (Anderson and Adey, 2011; Crichton et al, 2009; Shapiro, 1995), it will likely obscure both any notion of resilience as being formed through open-ended change and cannot address the interaction of changes in different systems evolving over different spatio-temporal scales. For Holling (1973; 2011), this process is crucial to the adaptive persistence, and transformation, of countless natural and social systems. Tellingly, we are not aware of any emergency planning exercises in the UK or elsewhere that have examined the unpredictable impact of long-term changes in infrastructure on immediate emergency response. Given this lacuna in resilience policy and practice, we now describe a heuristic tool that may be deployed to overcome the limitations of STSS perspectives on resilience in current resilience policy and practice.

\section{The Resilient Futures Project: Towards a Socio-Ecological View of Resilience}

\subsection{Methodology}


Scenario methodologies (Borjeson et al, 2006; Schwartz, 1996; Shearer. 2005; Varum and Melo, 2010) offer an important contribution to mobilising Hollingian socio-ecological concepts of resilience, especially as related to critical infrastructure. Scenarios have an established role in the planning and development of the built (and un-built) environment (e.g. Harty et al, 2007; Mokrech et al, 2012; Reginster and Rounsevell, 2006; Shearer, 2005). However, scenario techniques are seldom used to understand how future infrastructure systems, including emergency response itself, might, variously develop over the long-term, to promote or inhibit resilience. We can discern at least five barriers in examining the longer-term adaptive cycle of infrastructure change within resiliency planning: (i) the shortterm nature of political election cycles; (ii) the emphasis on immediate return on investment within private and public infrastructure operators and owners; (iii) the unpredictability of infrastructure change, especially in sectors such as ICT (iv) the lack of institutional legitimacy for long-term perspectives on resilience; and $(v)$ the absence of available tools and techniques capable of addressing such issues. While both (i) and (ii) are major obstacles in addressing any long-term policy issues, (iii), (iv) can, as examined below, be addressed through the development of (v). This section describes such a tool.

Between 2010 and 2013 the EPSRC Resilient Futures research project (see Resilient Futures, 2012) developed, and stress-tested through multi-stakeholder engagement, energy and transport orientated scenarios for 2050, each with radically divergent configurations of 
infrastructure. The Resilient Futures scenarios ${ }^{2}$ are explorative rather than predictive or normative: they are intended to explore possibilities for future changes in energy and transport infrastructure, in response to long-term drivers (such as climate change), rather than predict specific changes or offer a roadmap for responding to change (see Borjeson et al., 2006: 727). Importantly, these future infrastructure scenarios were not simply discussed by stakeholders to evaluate their general resiliency attributes. They were also stress-tested through the introduction of event-episodes in industry focus groups that functioned as quasi-emergency planning exercises. This twin-fold evaluation of the scenarios, both in static (as examined in semi-structured interviews) and more dynamic terms (as examined when scenarios were stress-tested by episodes within multi-stakeholder focus-groups), enabled us to capture any tensions between individual notions of their expected resiliency and the dynamic resiliency attributes that are only made manifest when practitioners work through an unfolding event. Moreover, by linking together longer-term, unpredictable changes in infrastructure development with short-term emergency response, our scenarioepisode tool challenges the STSS perspective of resilience, wherein short-term, system stability frames all resilience strategies.

Drawing upon, and developing, existing futures methods (see Borjeson et al., 2006; Schwartz, 1996), we developed our scenarios and episodes in consultation with a wide group of stakeholders: high-level public and private sector practitioners with a stake in the resiliency of UK transport and energy infrastructure (this user-group has chosen to remain

\footnotetext{
${ }^{2}$ For some, the use of scenarios here is inconsistent with their original meaning. Shearer (2005: 74), for example, makes a distinction between snapshots of alternative future and scenarios as pathways to that future. Despite such concerns, the definition of scenarios employed here is consistent with its use in many scenario studies in the infrastructure field and hence is the term most familiar to our user-group.
} 
anonymous given the highly confidential nature of their work). This process involved a seven-step procedure in which we constructed scenario-episodes to examine energy and transport infrastructure resilience in the face of natural and malicious hazards (this methodology is described in full in Sircar et al., 2013). We deployed the procedure for Resilient Futures as follows:

1. Review of extant infrastructure-related scenarios (listed in full in Sircar et al., 2013).

2. Distil two primary drivers for system adaptation from existing studies to create scenario axes.

3. Cross-reference features from extant scenarios to conduct a PESTEL analysis to identify basic scenario characteristics.

4. Refine and populate scenario details drawing on interview data with key stakeholders.

5. Develop narratives of the four future infrastructure scenarios.

6. Develop episodes to stress test scenarios. Conduct further interviews with different key stakeholders to check the plausibility of the episodes alongside the scenarios.

7. Deploy and evaluate integrated scenario-episode narratives within multi-stakeholder focus groups.

\subsection{Outcomes}

During stages one and two of the above process we identified a series of drivers for infrastructure change at a variety of geographical scales: 
- Uncertain impact of global climate change

- Growing global energy insecurity driven by transition from fossil fuel economy

- Growing global fuel and transport poverty caused by increasing global energy costs

- Growth of BRICS ${ }^{3}$ nations

- Ageing population in UK

- Population growth in UK

All of these drivers will likely induce an adaptive cycle of conservation and transformation in current energy and transport infrastructure systems. However much uncertainty remains regarding the precise response to such drivers for change. Major explorative futures studies (IPCC, 2000; Foresight, 2006; 2008) have identified broad areas of possible infrastructure changes:

- The balance of infrastructure decentralization/independency versus centralization/interdependency.

- The extent to which social prosperity is presaged by greater technological innovation, including reciprocal infrastructure investment.

\footnotetext{
${ }^{3}$ Brazil, Russia, India, China and South Africa
} 
These ambiguities over infrastructure change were translated into the differentiating axes of infrastructure uncertainties that, in turn, served to guide the production of the four Resilient Futures scenarios (see Figure 1).

[FIGURE 1 HERE]

Differentiating variables and values for these scenarios were generated through a PESTEL (Political, Economic, Social, Technological, Environmental and Legal) analysis of the scenario reports in Table 1. A full description of this analysis is provided in Sircar et al., (2013).

This PESTEL analysis produced short scenario narratives (see Sircar et al., 2013) which were then validated by a focus group of experts $(n=7)$ from the fields of infrastructure planning and resilience. The participants at this focus group formed the steering group for the project and would later form a key end-user group for outputs from the research. The scenarios were then refined through a series of semi-structured interviews $(n=29)$ conducted with a targeted sample of infrastructure planners and managers in energy and transport, spanning private and public organisations, including those with a specific interest in infrastructure resilience (Sircar et al., 2013). This group was asked three broad sets of questions:

1. How would the energy and transport systems operate in a healthy way?

2. How will the energy and transport systems relate to one other? 
3. What are the potential resilience strengths and weaknesses of each scenario?

The interview process was organised so that at least five interviewees discussed each scenario to ensure parity of coverage; however interviewees were able to consider any number of the four scenarios. The first two groups of questions were designed to elicit more information to further refine the scenario narratives. The third group of questions explicitly related to resiliency issues.

While asking practitioners general resiliency questions about a particular infrastructure scenario is a valuable way for practitioners to consider the variegated ways infrastructure systems may adapt to threats over the long-term (and thus promote a socio-ecological understanding or resilience), it has limitations. In particular resilience stakeholders are unable to consider how they might respond to an unpredictable and unfolding event within a specific scenario. And thus practitioners will tend to consider the resiliency of a scenario as being socially and geographically isomorphic: all people in all areas in scenario are identified as being more or less resilient in these general ways. While such general statements may offer useful starting points for moving discussion beyond an STSS perspective, they lack a level of precision about the different effects of hazards on different populations and regions which is demanded in understanding the complexities of resilience (Manyena, 2006).

In order to address such limitations, our tool includes stress-testing of the resiliency features of the scenarios through the development of threat episodes. Two episodes were 
generated that sought to engage with the maximum number of stakeholders. To aid comparability, the episodes adopt a similar starting point in each scenario, but resonate slightly differently within each setting in order to attenuate their implications and understand their impact within the differing contexts. A final consideration was the importance of engaging participants: episodes were developed that were plausible (Anderson and Adey, 2011) yet were also sufficiently extreme to stress-test infrastructural features of the scenarios. This challenging process was empirically informed through the analysis of official investigations of past natural (Katrina Report, 2006) and malicious events (9/11 Commission Report, 2004; 7/7 Coroner's Report, 2011), and was validated through interviews with security practitioners $(n=4)$. The final narrative involved a compound and developing crisis event in which a natural hazard episode (a tidal flood event) is followed (and compounded) by a malicious hazard episode (a terrorist attack on a power station).

\subsection{Integration of Scenarios and Episodes}

After the completion of the scenario and episode development, focus groups were conducted ( $n=5$ per group) for each of the four scenarios to help understand the on-going resiliency implications of future infrastructure changes. The use of focus groups to inform the development of scenarios is not new (Borjeson et al, 2006; Cairns et al, 2010; Goodier et al, 2010; Schwartz, 1996). However, in this instance, the focus group participants were explicitly told to immerse themselves in the scenario rather than to question, validate, or

develop them. The focus groups were comprised of stakeholders in various sectors related 
to critical infrastructure across national, regional and local scales, within private and public sector organisations. This immersion process was facilitated through the development of an animated presentation that introduced a selection of qualities attributed to the scenario in question. Each focus group effectively functioned as a future emergency response exercise. After the presentation and a brief discussion regards points of clarification, the first episode was immediately (verbally) introduced. Participants were asked to describe how the various agencies in each scenario were likely to respond to this episode, and importantly how the communities affected would respond. After this initial discussion regarding the recovery process, the second episode was then introduced. The surprise introduction of new threats during an emergency response exercise is an established technique, where the "aim is to stimulate the fog of an incident" (Adey and Anderson, 2011: 2891). It also enabled the cumulative and cascade impacts of natural and human-induced events to be evaluated. The participants were then asked how they would respond and how this event would influence, affect or inhibit the on-going recovery process and future infrastructure function. After this discussion a larger focus group with all participants $(n=20)$ from the four separate focus groups was conducted wherein the differing resilience features of each scenario were compared, contrasted and discussed as a group in more detail. This discussion also included some reflection upon different notions of resilience.

\section{Discussion: re-thinking resilience in socio-ecological terms}


All of the interviews and focus groups were recorded, transcribed and coded (using a hierarchical coding approach in QSR Nvivo 8), wherein the operation and resilience strengths and weaknesses of the infrastructure systems in each scenario could be analysed, including specific emergency response behaviours. Indicative results of this process are illustrated in Table 1 below:

[INSERT TABLE 1 HERE]

The future scenarios approach described here is intended as a means of moving beyond the STSS view of resilience which underpins much extant resilience policy and practice. More specifically, we propose that our heuristic tool will mobilise calls for socio-ecological understandings of infrastructure resilience (e.g. Holling 1973; 2001) and inform current policy and practice (for example emergency planning exercises). In this approach infrastructure practitioners should be prompted to unpack the interactions between systems of infrastructure (e.g. transport, energy, emergency response) evolving on much longer adaptive cycles, and thus question the sole focus on quantitative structural stability expressed in notion of robustness, reliability and hardening as the end-point of resilience. Findings from the Resilient Futures research exercise illustrated opportunities and challenges in developing this approach.

The first stage of the application of the tool involved a review extant future studies of infrastructure (see Table 1). All of these studies suggested various drivers that will induce 
adaptations in current infrastructure configurations over the long-term. While these reports tend to stress the uncertainty in the response of infrastructure to such drivers, they challenge the STSS assumption that the modus operandi of thinking about resilient infrastructure systems necessarily corresponds to ensuring their short-term, stability. An extract from The Powering our Lives futures report (Foresight, 2008), illustrates how the UK Government Office for Science has previously acknowledged how future adaption in infrastructure to drivers such as climate change will have varied resiliency implications:

In the Carbon Creativity scenario there are also large scale engineering solutions for resilience, such as higher flood defences and larger diameter drainage pipes, exploiting new, lower-carbon, concrete technologies.... In the Resourceful Regions scenario, the rise of geopolitical concerns and a dwindling of trust are allied with a strong role for regions to respond to local vulnerabilities and exploit local resources. Smart metering is imposed in many regions to reduce the risk of outages (Foresight, 2008: 148).

These two scenarios were not defined around their infrastructure configuration; instead they were differentiated on the basis of purely of the level of openness and interdependences in societies, as they respond differently to global drivers for change such as climate change and energy security. Notably, these Foresight scenarios mirror those proposed by the emissions scenarios developed by the United Nations Intergovernmental Panel on Climate Change (IPCC), wherein the effects of climate change could either foster 
local or global responses, and concomitant levels of infrastructure centralisation and integration (IPCC, 2000). However, while evidence exists that, at least in the UK, governments show some acknowledgement of the adaption of infrastructure over the longterm and its resiliency implications, this work is not cited within any key policy documents on UK resilience (see for example Cabinet Office, 2010; 2011). Such detachment is perhaps hardly surprising given that UK resilience policy has largely been framed as a response to perceived short-term failings such as those experienced after the 2007 summer flooding (Cabinet Office, 2011). Moreover, the Powering our Lives report is not focussed on infrastructure resiliency, but rather sustainability in the built environment. And yet other Foresight reports, such as the Intelligent Infrastructures scenarios (Foresight, 2006), which do focus on infrastructure change, remain similarly detached from long-term resiliency thinking.

During the refinement and testing of the Resilient Futures scenarios with stakeholders, we encountered many examples of the resiliency implications of long-term infrastructure adaption that could inform policy formulations. For example, one interviewee, a transport systems expert, analysed the Local Power for Local People scenario, and suggested that active modes of transport could encourage greater adaptation of urban transport infrastructure to localized flooding: 
You're not getting stuck, you know, in a whole line of traffic that can't go anywhere ... is walking and cycling inherently more resilient than using vehicles of some nature? I guess it is in some ways.

Thus, we can start to appreciate how response and recovery, one of the four ' $\mathrm{Rs}$ ' of resiliency concerns of the UK cabinet office (see Cabinet Office, 2011), might be encouraged in a practical manner by planning for more cycle lanes and pedestrian friendly highways. Such ideas were elaborated in other interviews. For example, another interviewee, again with an expertise in transport, questioned the limitations of this idea:

if it was saying walking and cycling were the main forms of passenger transport then we need to do some fairly radical things. Fairly radical things would have to happen for resilience to be a big problem, although a heavy snowfall might be such a feature, clearly walking and cycling becomes more difficult when there is heavy snowfall.

Conversely in such a highly localised infrastructure scenario the amount of redundancy would clearly be reduced. For example, as communities became more reliant on singlesources of electrical power, instead of being able to easily share power across a national grid. Several interviews and focus groups noted this point in relation to both of the localised scenarios (High-Tech Hamlets, and Local Power for Local People). The full implications of this lack of redundancy were captured in one of the focus groups stress-tests for Local Power for 
Local People, where one respondent explained how: "the thing is, in this world everything is essential". Or, as another respondent put it:

In this one, they inevitably will suffer a lack of resilience because of small scale. Eventually you get down to the fact that you only need one of something because you are so small and so if that one that has an issue, you have had it.

It is beyond the scope of this conceptually and methodologically orientated paper to discuss the policy implications of such issues. The important point we stress here is that such discussions were being elicited from practitioners following the method described in section three. One research subject, with a background of high-level engagement with the UK government on infrastructure policy, made this point forcibly to us during interview:

when you hear Government Ministers talk about resilience, what they mean is how do you build in increased resilience around our existing infrastructure, around a pattern of infrastructure we've got today, not how do we re-engineer the infrastructure to build in resilience and, for me, there's a massive difference there, massive difference, they just want to take the existing system, they're extrapolating the existing system out for ' $x$ ' decades. 
I think that's the opportunity you've got here is to take away any of the comfort factors they may still have about how to increase resiliency in infrastructure systems and infrastructure maintenance, because that way there'll be much more creative thinking about what we need to do.

We do not intend the heuristic tool presented here to provide detailed policy descriptions. To repeat an earlier point, the tool presented here is not intended to offer predictive or normative scenarios that could form the basis of policy prescriptions. Rather we simply aim to elicit explorative debate and discussion around the significance of longer-term adaptive cycles in existing infrastructure, in response to various drivers, and then assess the shorterterm resiliency implications of these changes. In provoking these discussions, we of course recognize that policymakers are involved in making investment decisions now that will shape future infrastructure change, especially given the long life-cycle of energy and transport infrastructure assets, and thus these scenarios might elicit discussion which could inform whether current decisions are framed as being even connected to resilience. One interviewee explained how:

The government has a big pot of money to invest for 2050, let's make sure that the allocation of that capital is designed against a whole set of upstream resiliency issues, not simply factored in against an old way of looking at energy infrastructure. 
The Resilient Futures research exercise also helped practitioners identify trade-offs between different aspects of resilience, as related to infrastructure change. For example, a scenario where infrastructure is more independent and de-centralised might aid response and recovery by encouraging greater self-sufficiency. Yet such isolated communities may suffer from a lack of redundancy in energy production because energy is not shared so readily. In other words, while greater infrastructure decentralisation and independence may prevent regional cascade failures from localised events such as flooding, and thus enhance nationallevel resilience, it can increase vulnerability within communities to such events. The notion that increased community independence actually upscales resilience is we argue a fascinatingly counter-intuitive issue that requires further examination.

Such insights have important implications. Current definitions of resilience, such as those offered by the UK Cabinet Office and the UNISDR, tend to view different concepts of resilience as mutually compatible. However, discussions in our focus groups and interviews identify important trade-offs to consider when focussing on different dimensions, and indeed scales, of resilience (e.g. increased community resilience may inhibit national resilience). This especially applies when considering the implications of long-term adaptations in infrastructure systems. Many of these trade-offs, and interactions between different spatio-temporal scales of resilience, are captured in Table 1. In conceptual terms, the Resilient Futures approach proved highly successful in helping practitioners consider how infrastructure systems, such as energy and transport infrastructure, may adapt across long-term cycles. The approach also revealed how such adaptation might induce and constrain changes in other infrastructure systems with shorter and smaller adaptive cycles, 
such as emergency response practices. In this regard we suggest these insights correspond well with Holling's socio-ecological understanding of resilience. However, it was notable that our tool was less successful in addressing interactions in the other direction: how changes in micro-scale emergency response in turn influence macro-scale infrastructure planning. This bias towards descending rather than ascending cross-scale interplay may be partly explained by the static use of the scenarios in the episode focus groups: once the scenarios had been refined through interviews they served as static contexts for the episodes to play out, inhibiting discussion of how they might develop in the future. Some possibilities to address this limitation are outlined at the end of this paper.

\section{Concluding Comments}

The Resilient Futures project has developed and tested a novel 'scenario-episode' tool to address future infrastructure resilience in socio-ecological terms. Our approach thus rejects the idea, popular in future studies that adaptation is, as De Jouvenel (2000: 40) argues, antithetical to the notion of strategic planning. Adaptation is not purely a passive attitude towards the future, as in 'waiting to see what happens and adapt to it'. Rather, it can also be strategically anticipated, evaluated and enabled in different ways within particular infrastructure policies. This point thus also confounds any binary categorical distinction of resilience into proactive or reactive modalities (see Coaffee et al 2009: 132). The distinction between proactive and reactive modes of resilience is well-rehearsed in resiliency debates: proactive modes correspond to macro-scale (temporal and spatial), strategic infrastructure 
planning and reactive modes to micro-scale recovery and adaptation. Rather uniquely, findings from the use of our approach by practitioners suggest how micro-scale reactive resilience can be proactively influenced by macro-scale decisions and future framings of various agencies in the present (see Section 4, and especially Table 1). This insight is directly in accord with Holling's (2001) adaptive cycle model, where cross-scale interplay is integral to the self-organization, and indeed resilience, of any system. However, as Folke (2006) suggests, the implications of this cross-scale (both spatial and temporal) interplay are often underplayed within current resilience policy. In addressing this omission, we do not here seek to provide precise policy recommendations; rather we suggest the efficacy of a heuristic tool intended to help address such limitations. And thus, we seek to directly extend the full implications of Holling's theory of resilience from academic to policy analysis, as opposed to simply conceptualizing its potential (as in Folke, 2006; Manyena, 2006)

We advocate this tool not simply because of its capacity to capture the resiliency consequences of the interaction between different systemic scales, but also because in so doing we problematize many long-held assumptions found with STSS thinking, from the tendency to assume all notions of resilience are mutually compatible to the wide-spread conflation of system stability and resilience. As shown above, such concepts remain pervasive across government policy (Cabinet Office, 2010; 2011; Patriot Act, 2001; UN, 2005), as well as academic analysis (Xu et al, 2012; Maliszewski and, Perrings, 2012). Nevertheless, this tool is not intended to replace all current resilience approaches. Indeed, STSS thinking is unavoidable when considering short-term resiliency policy and practice (see Anderson and Adey, 2011; Crichton et al, 2009; Shapiro, 1995). However, the exclusive 
application of such thinking to elucidate the resiliency of longer-term urban and regional planning in areas like infrastructure is, as we have implored to stress, highly problematic.

In order to further refine this tool a later phase of the Resilient Futures scenarios will inform a subsequent series of complex computer models that will allow user-specific interactions with the scenarios. Therefore, for example, the specific agency of a particular domain (e.g. rail network maintenance) can be incorporated, and technical interdependencies can be modelled as complex causal relationships rather than simply relayed within a workshop setting of diverse participants. This later phase will involve the construction of a suite of interactive computer-based simulations through which different users, spanning different temporal and spatial scales, from infrastructure planners to emergency responders, can examine how their decisions might impact upon the resilience of infrastructure systems, communities, and individuals. Importantly, this complexity modelling will provide additional scope to address how micro-scale interactions in emergency response may have on-going effects on longer-term infrastructure planning, thus addressing ascending as well as descending cross-scale interplay. It is beyond the scope of this paper to provide a thorough outline of this on-going work; however it is important to recognize that such future simulation would be impossible without the initial development of this 'scenario-episode' approach through engagement with end-users, an approach that has already yielded valuable insights for practitioners into the socio-ecologies of future infrastructure resiliency.

\section{References}


9/11 Report (2004) The 9/11 Commission Report. W.W. Norton \& Company, New York.

7/7 Coroner's report (2011) 'Coroner's Inquest into the London Bombings of $7^{\text {th }}$ July 2005'. Coroner's Office, London, http://7julyinquests.independent.gov.uk/role_coroner/index.htm

Adey, P., and B. Anderson (2011) 'Event and anticipation: UK Civil Contingencies and the space - times of decision', Environment and Planning A. 43(12). pp. $2878-2899$

Adger, N. (2000) 'Social and ecological resilience: are they related?'. Progress in Human Geography. 24(3). pp. 347-364.

Anderson, B., and P. Adey (2011) 'Affect and security: exercising emergency in 'UK civil contingencies' Environment and Planning D: Society and Space. 29(6). pp.1092-1109

Borjeson, L., M. Hojer K-H. Derborg T. Ekvall and G. Finnveden (2006), 'Scenario Types and Techniques: Towards a User Guide'. Futures 38. pp. 723-739.

Bosher, L., and A. Dainty (2011) 'Disaster risk reduction and 'built-in' resilience: Towards guiding principles for construction practice' Disasters, 35(1). pp.1-18. 
Cabinet Office (2010) 'Strategic Framework and Policy Statement on Improving the Resilience of Critical Infrastructure to Disruption from Natural Hazards'. Cabinet Office, London, http://webarchive.nationalarchives.gov.uk/+/http://www.cabinetoffice.gov.uk/media/3491 03/strategic-framework.pdf.

Cabinet Office (2011) 'Keeping the Country Running: Natural Hazards and Infrastructure'. Cabinet Office, London, http://www.cabinetoffice.gov.uk/sites/default/files/resources/natural-hazardsinfrastructure.pdf.

Cairns, G., G. Wright. K. Van der Heijden, R. Bradfield and G. Burt. (2010) 'Enhancing foresight between multiple agencies: Issues in the use of scenario thinking to overcome Fragmentation'. Futures 38. pp. 1010-1025.

Coaffee, J. D. Wood and P. Rogers (2009) The Everyday Resilience of the City: How Cities Respond to Terrorism and Disaster. Palgrave: Basingstoke.

Crichton, M., C. Ramsay and T. Kelly (2009) 'Enhancing Organizational Resilience Through Emergency Planning: Learnings from Cross-Sectoral Lessons', Journal of Contingencies and Crisis Management. 17(1). pp. 24-37 
CRS (2004) 'Critical Infrastructure and Key Assets: Definition and Identification', Library of Congress Congressional Research Service, Washington D.C.

http://www.fas.org/sgp/crs/RL32631.pdf

De Jouvenel, H. (2000) 'A Brief Methodological Guide to Scenario Building'. Technological Forecasting and Social Change. 65. pp. 37-48.

Folke, C. (2006) 'Resilience: The emergence of a perspective for social-ecological systems analyses'. Global Environmental Change. 16. pp. 253-267.

Foresight (2006) 'Intelligent Infrastructure Futures The Scenarios - Towards 2055', Foresight, Office of Science and Technology, London, www.foresight.gov.uk.

Foresight (2008) 'Powering our Lives: Sustainable Energy Management and the Built Environment', Foresight, Government Office for Science, pp213, available at www.foresight.gov.uk, https://dspace.Iboro.ac.uk/2134/11656

Goodier S., S. Austin R. Soetanto and A. Dainty (2010) 'Causal mapping and scenario building with multiple organisations' Futures. 42. April 2010, pp. 219-229, http://dx.doi.org/10.1016/j.futures.2009.11.007. 
Guldi, J. (2012) Roads to Power: Britain Invents the Infrastructure State. Harvard University Press, Cambridge, Mass.

Harty, C., C. Goodier R. Soetanto. S. Austin A. Dainty and A. Price (2007) 'The Futures of Construction: a critical review of construction futures studies', Construction Management and Economics. 25(5). pp. 477-493, DOI:10.1080/01446190600879117.

Holling, C (1973) 'Resilience and stability of ecological systems', Annual Review of Ecology and Systematics. 4. pp. 1-23.

Holling, C. (2001) 'Understanding the Complexity of Economic, Ecological, and Social Systems, Ecosystems. 4. pp. 390-405

Holling, C., L. Gunderso and D. Ludwig (2002) 'In quest of a theory of adaptive Change'. In L Gunderson and C Holling (eds.) Panarchy: Understanding transformations in human and Island Press, Washington. pp. 3-22.

Hughes, T. (1983) Networks of Power: Electrification in Western society, 1880-1930. John Hopkins University Press, Baltimore, MD. 
Hughes, N., and N. Strachan (2010) 'Methodological Review of UK and International Low Carbon Scenarios', Energy Policy. 38. pp. 6056-6065.

IPCC (2000) 'IPCC Special Report Emissions Scenarios: Summary for Policymakers'. United Nations, Geneva, http://www.ipcc.ch/pdf/special-reports/spm/sres-en.pdf.

Katrina report (2006) 'Select Bipartisan Committee to Investigate the Preparation for and Response to Hurricane Katrina', Select Bipartisan Committee to Investigate the Preparation for and Response to Hurricane Katrina, Washington DC, http://www.katrina.house.gov/full_katrina_report.htm

Maliszewski P., and C. Perrings (2012) 'Factors in the resilience of electrical power distribution infrastructures'. Applied Geography. 32. pp. 668-679.

Maslow, A. (1987) Motivation and Personality. Pearson, London.

Manyena, S. (2006) 'The Concept of Resilience Revisited'. Disasters. 30(4). pp. 433-450.

Mokrech M., R. Nicholls. and R. Dawson (2012) 'Scenarios of future built environment for coastal risk assessment of climate change using a GIS-based multicriteria analysis', Environment and Planning B: Planning and Design. 39(1), pp. $120-136$. 
NIAC (2009) 'Critical Infrastructure Resilience Final Report and Recommendations', Department of Homeland Security, Washington DC, http://www.dhs.gov/xlibrary/assets/niac/niac_critical_infrastructure_resilience.pdf

Patriot Act (2001) ‘Uniting And Strengthening America By Providing Appropriate Tools Required To Intercept And Obstruct Terrorism (USA Patriot Act) Act Of 2001', U.S. Congress, Washington D.C. http://www.gpo.gov/fdsys/pkg/PLAW-107publ56/pdf/PLAW-107publ56.pdf

Paton, D., L. Smith. and J. Violanti, (2000) 'Disasters Response: Risk, Vulnerabilities and Resilience', Disasters Prevention and Management, 9(3) pp. 173-179.

Pandolfi, J., R. Bradbury. E. Sala P. Hughes K. Bjorndal R. Cooke D. McArdle L. McClenachan J. Newman. G. Paredes. R. Warner and J. Jackson (2003) 'Global Trajectories of the Longterm Decline of Coral Reef Ecosystems'. Science. 301, pp. 955-958.

Reginster, I., and M. Rounsevell (2006) 'Scenarios of future urban land use in Europe', Environment and Planning B: Planning and Design. 33(4) pp. 619-636.

Richardson, G. (2002) The Metatheory of Resilience and Resiliency'. Journal of Clinical Psychology. 58(3). pp. 307-321. 
Resilient Futures (2012) Resilient Futures EPSRC project, University of Southampton, http://r-futures.ecs.soton.ac.uk/overview/.

Schwartz, P. (1996) The Art of the Long View, John Wiley \& Sons, Chichester.

Shapiro, L. (1995) Training Effectiveness Handbook, McGraw-Hill, New York.

Shearer, A. W. (2005) 'Approaching scenario-based studies: three perceptions about the future and considerations for landscape planning', Environment and Planning B: Planning and Design. 32(1), pp. $67-87$.

Sircar, I., D. Sage C. Goodier P. Fussey, and A. Dainty (2013) Constructing resilient futures: integrating UK multi-stakeholder transport and energy resilience for 2050, Futures, http://dx.doi.org/10.1016/j.futures.2013.04.003

Smith, J. (2003) 'Civil Contingencies Planning in Government'. Parliamentary Affairs. 56, pp. 410-422. 
UKERC (2009) 'Making the Transition to a Secure and Low Carbon Energy System: Synthesis Report'. United Kingdom Energy Research Centre, London, http://www.ukerc.ac.uk/support/tiki-index.php?page=ukerc2050homepage

Varum, C., and C. Melo (2010) 'Directions in scenario planning literature - A review of the past decades',.Futures. 42. pp. 355-369.

Walker, J., and M. Cooper (2011) 'Genealogies of resilience: From systems ecology to the political economy of crisis adaptation'. Security Dialogue. 42(2). pp. 143-160.

Xu, W., L. Hong. L. He. S. Wang. and X. Chen (2012) 'Supply-Driven Dynamic Inoperability Input-Output Price Model for Interdependent Infrastructure Systems'. Journal of Infrastructure Systems. 17(4) pp. 151-162. 